\title{
Electron Microscopic Study on the Sinusoidal Wall of the Liver in the Flatfish, Kareius bicoloratus: Demonstration of Numerous Desmosomes along the Sinusoidal Wall
}

\author{
Yutaka Tanuma, Masako Ohata and Toshio Ito \\ Department of Anatomy (Prof. K. UchidA and Prof. T. ITo), Teikyo University School of Medicine, \\ Tokyo, Japan
}

Received February 4, 1982

\begin{abstract}
Summary. The liver of the flatfish, Kareius bicoloratus was observed by transmission electron microscopy.

The hepatocytes surround the bile canaliculi and are loosely disposed with few connections in between. The architecture of the hepatic tissue is first supported by junctional complexes between hepatocytes abutting on the bile canalicular lumen, second, by intraparenchymal bile ductules connecting with hepatocytes through desmosomes and third, by particular "desmosomal complexes" composed of numerous desmosomes arranged along the interhepatocytic space and accompanied by bundles of microfilaments in the cells. The fourth, and most important supporting factor of the hepatic tissue, consists of sinusoidal cells including adjacent hepatocytes connected by many desmosomes.

The Disse's space lacks collagen fibrils but contains filaments of type IV collagen. Sinusoidal cells are reinforced by abundant microfilaments in their cytoplasm. Desmosomes occur between endothelial cells, which are further connected by other desmosomes to hepatocytes as well as Ito cells. Desmosomes are most numerous around the Ito cells. Thus, the cells forming the sinusoidal wall are interconnected by many desmosomes, forming as a whole a strong framework which supports the hepatic tissue.

The desmosomes between the sinusoidal cells are characterized, except for those between endothelial cells themselves, by the presence of zones of microfilaments on both of their sides which extend parallel to the desmosomal plaques and are believed to strengthen the desmosomal connection.

No Kupffer cells could be identified in the sinusoid, but macrophages were demonstrated in the parenchyma near the Disse's space.
\end{abstract}

Notwithstanding an extensive and detailed light microscopic study on livers in a large variety of fishes and in adult lampreys (Cyclostoma) carried out by ITO, WATANABE and TAKAHASHI (1962), electron microscopic studies on the same subjects, especially on the cells of the hepatic sinusoidal wall, have been, so far as the present authors know, relatively limited. Recently, it has been demonstrated that some piscine livers show many desmosomal junctions between sinusoidal cells including hepatocytes (NoPANITAYA et al., 1979a, b; Tanuma and Ito, 1980; Fujita et al., 1980; Sakano ane Fujita, 1981; 
SHIN, 1981). This paper reports the results of an electron microscopic investigation of the flatfish liver with special attention to the desmosomal junctions between hepatic sinusoidal cells including hepatocytes.

\section{MATERIALS AND METHODS}

Livers used for this study were taken from flatfishes, Kareius bicoloratus, captured in the winter and spring. The livers were excised and fixed by perfusion via the blood vessel with a cold fixative containing $2.5 \%$ glutaraldehyde in a $0.1 \mathrm{M}$ phosphate buffer (pH 7.4). After perfusion fixation, the livers were cut into small pieces to be fixed with the same fixative for $2 \mathrm{hrs}$. They were rinsed several times in a cold $0.1 \mathrm{M}$ phosphate buffer containing $5 \%$ sucrose $(\mathrm{pH} 7.4)$ and left overnight in the same buffer at $5 \mathrm{C}^{\circ}$ They were postfixed with a $1 \%$ osmic acid solution in a $0.1 \mathrm{M}$ phosphate buffer containing $5 \%$ sucrose $\left(\mathrm{pH} \mathrm{7.4)}\right.$ at $0^{\circ} \mathrm{C}$ for 90 min. Following dehydration in graded ethanol, the tissue pieces were embedded in Epon 812 and sectioned with a Porter-Blum

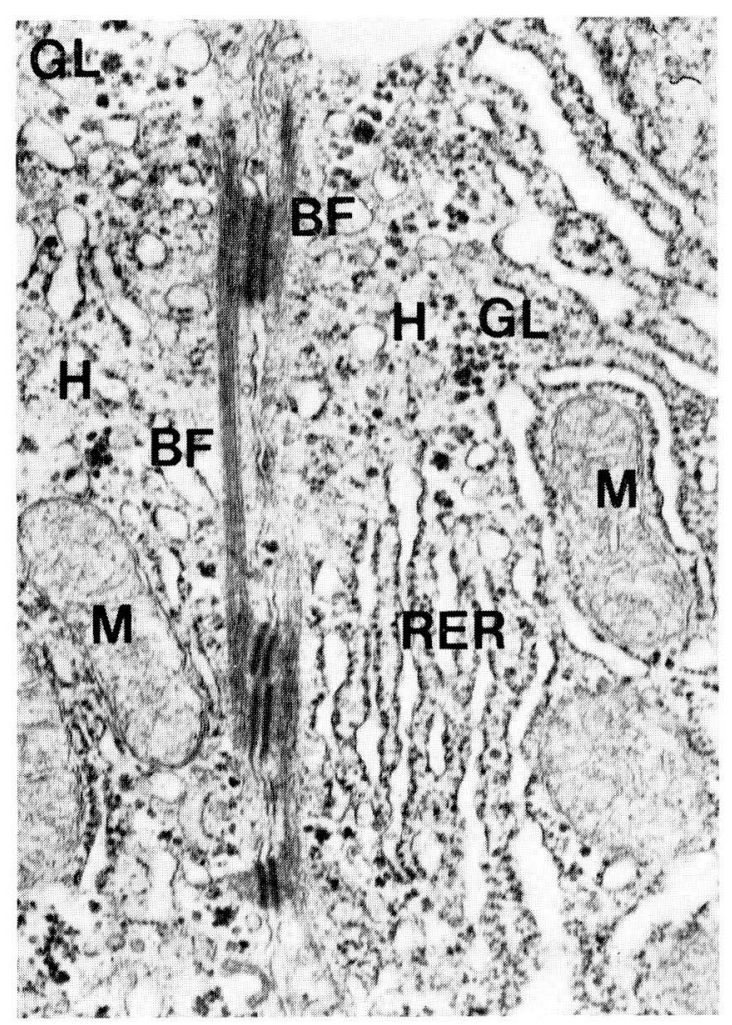

Fig. 1. A "desmosomal complex" between hepatocytes (H) found near the interhepatocytic bile canaliculus. Four desmosomes disposed at variable intervals, are accompanied with bilateral straight bundles of microfilaments ( $B F$ ) running along the plasma membrane. GL glycogen particles, $M$ mitochondria, cisternae of RER. Flatfish liver. $\times 25,000$
Ultra-Microtome MT2-B. The ultrathin sections were stained with a saturated uranyl acetate and Sato's lead solution. Electron micrographs were taken with a JEM-100C electron microscope.

\section{RESULTS}

\section{Hepatic parenchyma}

Hepatocytes are arranged around the bile canaliculi like a tubular gland, into which they project many slender finger-shaped microvilli. The interhepatocytic spaces are irregular in breadth, showing dilated portions at random places into which hepatocytes send out microvilli or short bulbous processes.

The intercellular spaces are sealed by junctional complexes abutting on the bile canaliculi; on the opposite side they empty into the Disse's space forming generally wide recesses. Solitary desmosomal junctions are rarely found between adjacent hepatocytes, but occasinally occurring near the bile canaliculi are peculiar junctional structures composed of variable numbers of desmosomes lined up successively at more or less short intervals. One of these 
"desmosomal complexes" is depicted in Figure 1; four desmosomes are gathered at different intervals along the intercellular space. A more extensive "desmosomal complex" is seen in Figure 2; it is composed of about 14 desmosomes closely aligned. On both side of the desmosomal complexes, compact straight bundles of microfilaments course both close to and parallel to the plasma membrane. In higher magnification

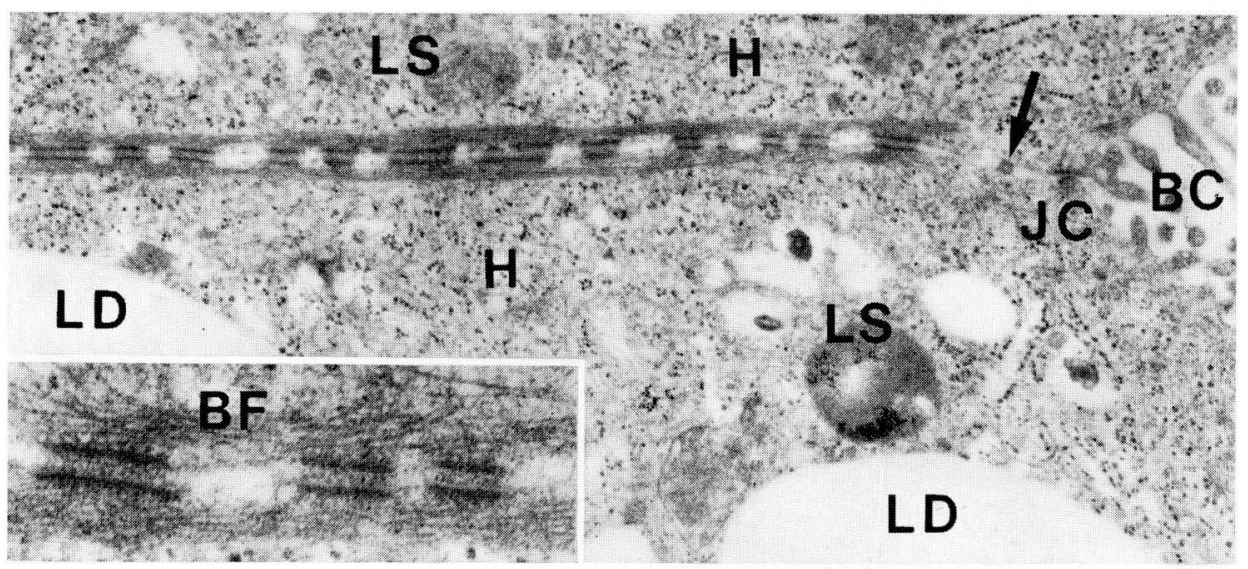

Fig. 2. A longer "desmosomal complex" between hepatocytes $(H)$ accompanied with bilateral microfilament bundles. Numerous desmosomes line up along the intercellular space with short intervals. $B C$ bile canaliculus, $J C$ junctional complex, the arrow indicates the desmosome of the junctional complex, $L D$ lipid droplets in hepatocyte, $L S$ lysosome. Flatfish liver. $\times 17,800$. Inset: A higher magnification of a short segment of the above desmosomal complex. Filaments originating from the filament bundles $(B F)$ terminate at the attachment plaques of the desmosomes. Apposed plasma membranes of the hepatocytes are insufficiently preserved. $\times 52,000$

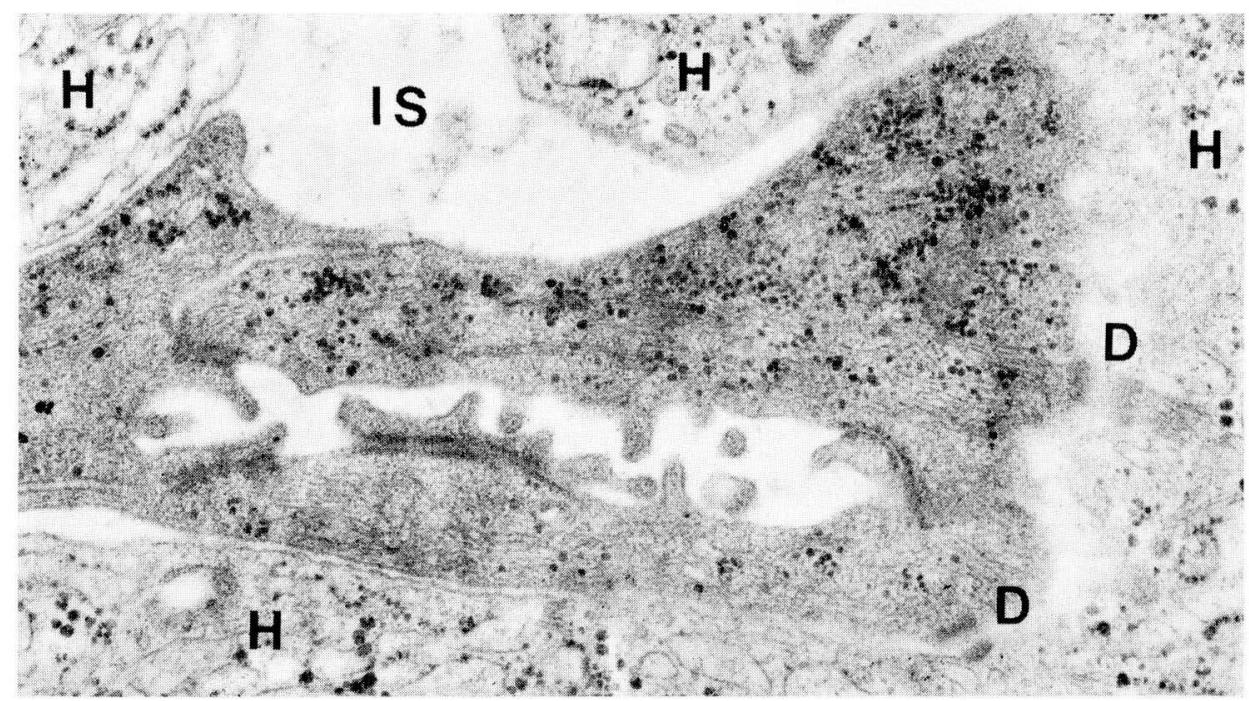

Fig. 3. An oblique section of a small intralobular bile ductule surrounded by a simple flat epithelium. Electron dense cytoplasm of each epithelial cell is characterized by abundant microfilaments and numerous ribosomes mingled with glycogen particles. Epithelial cells are connected with hepatocytes $(H)$ through desmosomes $(D)$. IS intercellular space. Flatfish liver. $\times 32,500$ 
(Fig. 2, inset), microfilaments derived from the filament bundles are observed to diverge toward the desmosomes to anchor their attachments or desmosomal plaques.

In the interhepatocytic space, profiles of small intralobular bile ductules are frequently encountered, often showing communications with the bile canaliculi. The ductules are lined by a simple flat epithelium which protrudes a few finger-shaped microvilli into the narrow lumen (Fig. 3). The ductular epithelium lacks a basal lamina. The cytoplasm of epithelial cells is characterized by its dark appearance and abundance of microfilaments oriented random directions. In addition, numerous free polysomes are distributed throughout the cytoplasm mingled with less numerous glycogen $\beta$-particles. The intercellular space between the epithelial cells is sealed by a junctional complex abutting on the ductular lumen. Several desmosomes are detected between the epithelial cells and adjacent hepatocytes, and microfilaments from both cells converge on these desmosomes (Fig. 3).

\section{The perisinusoidal space}

The perisinusoidal or Disse's space contains numerous microvilli of hepatocytes, fatstoring cell of Ito and fine filaments oriented in random directions.

a. Hepatocytic microvilli are slender cytoplasmic processes devoid of organelles, and their concentration is variable from place to place. They are roughly oriented

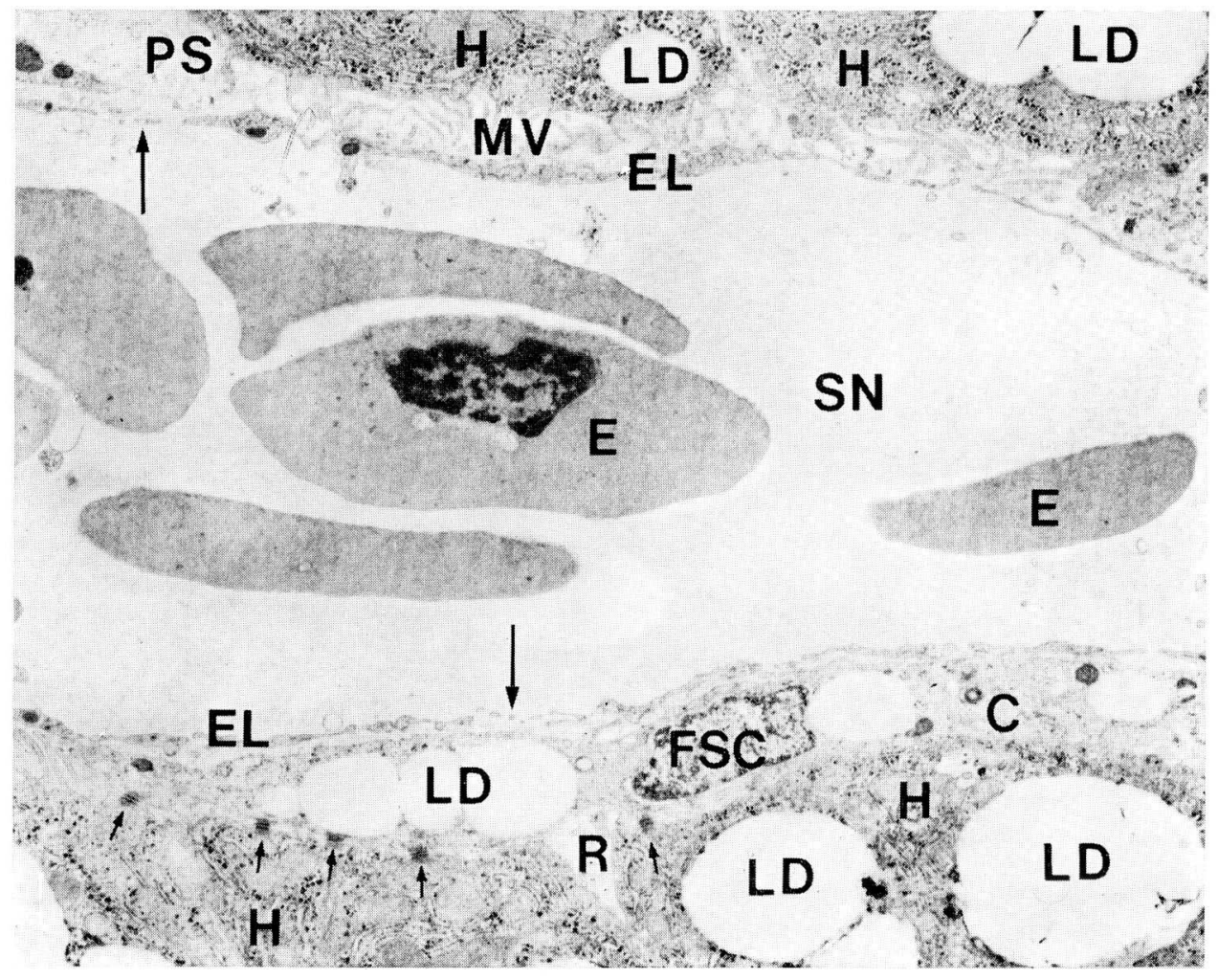

Fig. 4. Survey picture of the sinusoidal wall of the flatfish liver. An Ito cell ( $F S C$ ) containing lipid droplets $(L D)$ is elongated along the sinusoidal wall and is connected to hepatocytes $(H)$ by many desmosomes (small arrows). C centriole, $E$ erythrocytes, $E L$ endothelial lining of the sinusoid ( $S N$ ), $M V$ hepatocytic microvilli, PS Disse's space, $R$ recessus of the interhepatocytic space, the arrows indicate sieve plates. $\quad \times 7,000$ 
towards the endothelial lining, exhibiting wavy curves (Fig. 4).

It is a new and noteworthy finding that the hepatocytic microvilli of the flatfish frequently end in a vesicular swelling measuring approximately $140-200 \mathrm{~nm}$ in diameter (Fig. 5, 8). Larger vesicles are considered to be invested merely in the plasma membrane. Smaller ones may also be observed in the axial cytoplasm of the microvilli.

b. Sinusoidal endothelial cells incompletely separate the Disse's space from the hepatic sinusoid. Like the mammalian sinusoidal endothelium, they are composed of perikarya or nucleus-containing cell bodies and membraneous cytoplasmic processes which are discontinuous, showing fenestrae devoid of diaphragma (Fig. 5). Clusters of fenestrae form the "sieve plates" (Fig. 4, 5, 10,13). They are usually found in the

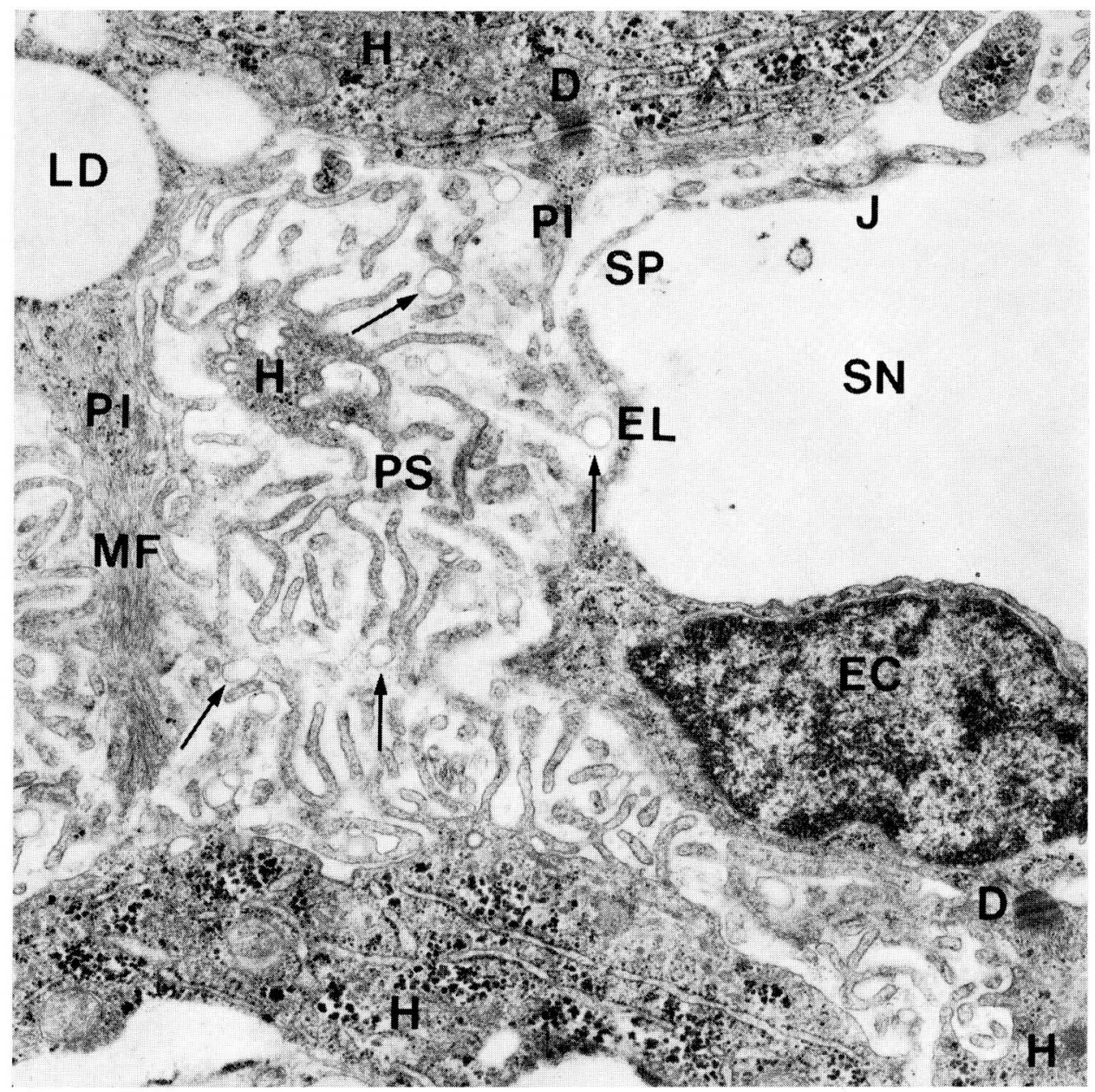

Fig. 5. Hepatocytic microvilli and cytoplasmic processes (PI) of an Ito cell in the Disse's space $(P S)$. They are separated from the sinusoid (SN) by the perikaryon (EC) and the process (EL) of the sinusoidal endothelium. Some microvilli of the hepatocytes possess a vesicle (arrows) at their end. Desmosomes $(D)$ are observed between the hepatocyte $(H)$ and the cytoplasmic process of Ito cell as well as between the hepatocyte process $(H)$ and the endothelial perikaryon. $L D$ lipid droplet, $M F$ microfilaments in Ito cell processes Endothelial lining exhibits a sieve plate $(S P)$ and a junction $(I)$ between endothelial processes. Flatfish liver. $\times 16,800$ 
thinner portions of the cytoplasmic extensions as in mammalian hepatic sinusoidal endothelium (Wisse, 1970). The endothelial lining is devoid of a basal lamina.

The majority of organelles are gathered in the perinuclear cytoplasm, but a few of them may occur in the thicker portions of the cytoplasmic processes. The most conspicuous organelles are dense bodies of probable lysosomal nature (Fig. 6, 7) which may be of a considerable amount in occasional cells (Fig. 7). A few small mitochondria are detected in the perikaryon (Fig. 6). A small Golgi complex is found on one side of the nucleus. A centriole may sometimes be identified in the Golgi area (Fig. 7). Cisternae of the rough endoplasmic reticulum (RER) are scanty, short and flat in profile, whereas

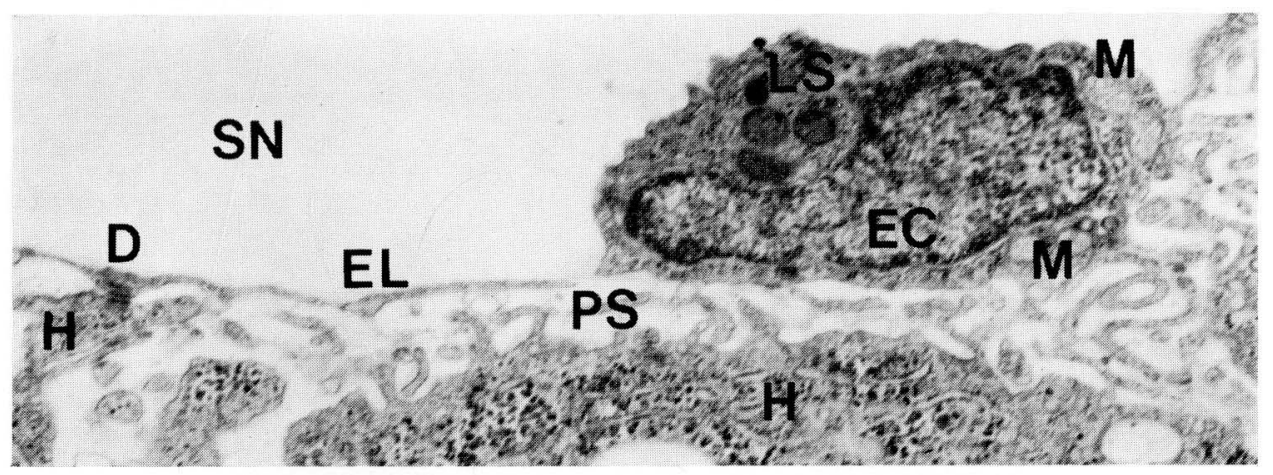

Fig. 6. Sinusoidal endothelial cell body (EC) containing several lysosomes (LS) and a few small mitochondria $(M)$ around the nucleus. Cytoplasmic process $(E L)$ is connected through a desmosome $(D)$ with cytoplasmic process of hepatocyte $(H)$. PS Disse's space containing hepatocytic microvilli, SN sinusoid. Flatfish liver. $\times 13,500$

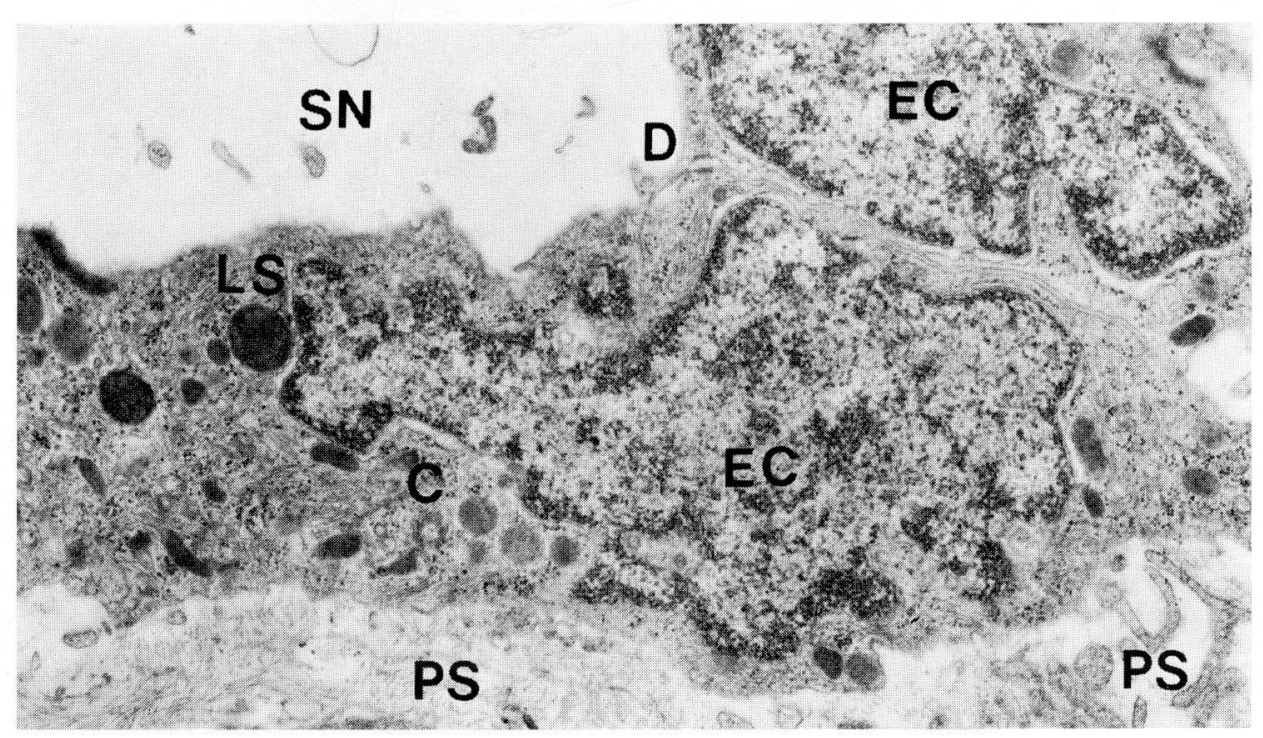

Fig. 7. Close connection between adjacent endothelial perikarya (EC) containing irregularshaped nucleus, many lysosomes (LS) and abundant microfilaments. Between the closely adjacent perikarya a long intimate apposition of plasma membranes exists leaving a space about $200 \AA$ wide. A desmosome (D) is revealed there. C centriole, PS Disse's space containing delicate filaments (type IV collagen) and sparse hepatocytic microvilli, SN sinusoid Flatfish liver. $\times 15,000$ 
free ribosomes are numerous and distributed not only in the perikaryon but also in the thicker portions of the cytoplasmic extensions. In the perikaryonal cytoplasm, extraordinarily numerous microfilaments are revealed running in irregular directions, and forming small bundles (Fig. 7, 8); they extend also into the cytoplasmic extensions, even into their thinner portions (Fig. 9). The microtubules are not distinct. Both in the perikaryon and in the cytoplasmic extensions, ultrastructural features suggestive of the micropinocytotic activity of the endothelial cell are rare, and only coated invaginations of the plasma membrane are occasionally detected (Fig. 8). Connections between neighboring endothelial cells in the flatfish liver sinusoid do occurs, first, between adjacent perikarya, second, between a thicker portion of the cytoplasmic extension and a perikaryon and third, between juxtaposed margins of the thicker portions of cytoplasmic processes (Fig. 7-9,17). In these three cases, closely apposed plasma membranes come into contact across a $200 \mathrm{~A}$ wide intercellular space. This parallel apposition of juxtaposed plasma membranes probably corresponds to the "junctional complexes" proposed by WISSE (1970). In the flatfish liver, a desmosome occurs within the area of this membrane apposition; in Figure 7, 8, and 9, a desmosome is visible on which cytoplasmic filaments converge to anchor their attachment plaques. On the

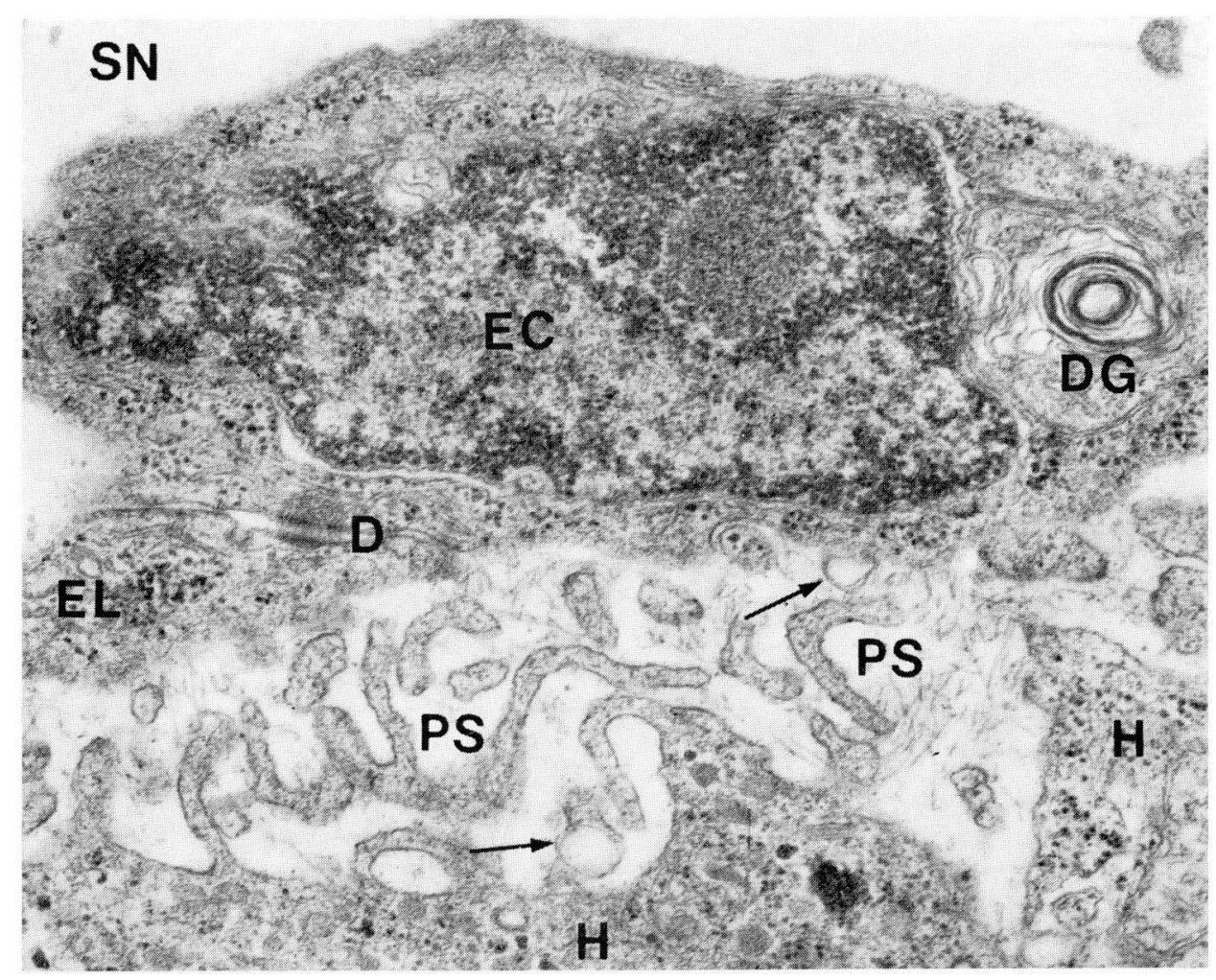

Fig. 8. Connection between endothelial perikaryon (EC), containing a nucleus, degenerated Golgi complex ( $D G$ ) and many microfilaments and thickened end part of the cytoplasmic extension (EL) of a neighboring endothelial cell. The plasma membranes of both cells are juxtaposed for a long distance and are connected by a desmosome $(D)$. Near the desmosome a coated invagination of plasma membrane is visible. In the Disse's space (PS), microvilli of hepatocyte $(H)$, vesicles (arrows) at their distal ends and many filaments (type IV collagen) are seen. SN sinusoid. Flatfish liver. $\times 32,500$ 


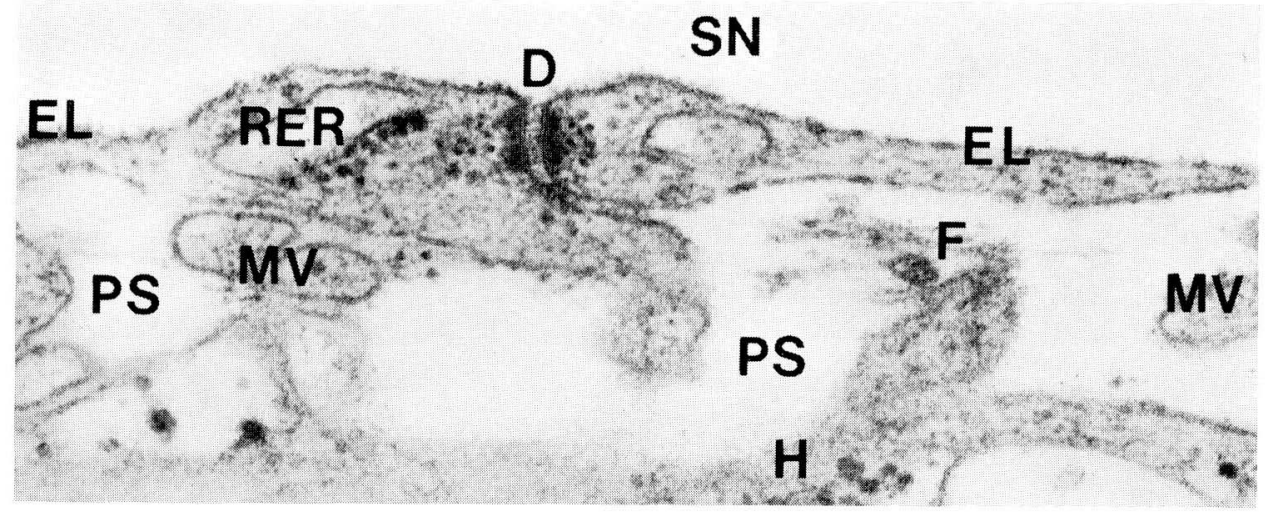

Fig. 9. Connection between thickened end parts of cytoplasmic processes ( $E L$ ) of neighboring endothelial cells. Plasma membranes of both cells are closely apposed for a considerable distance and are connected by a desmosome $(D)$. In the cytoplasmic processes, cisternae of $R E R$ and cytoplasmic microfilaments are seen. $F$ a minute bundle-like accumulation of filaments (type IV collagen), $H$ hepatocyte, $M V$ microvilli of hepatocyte, $P S$ Disse's space, $S N$ sinusoid. Flatfish liver. $\quad \times 70,000$

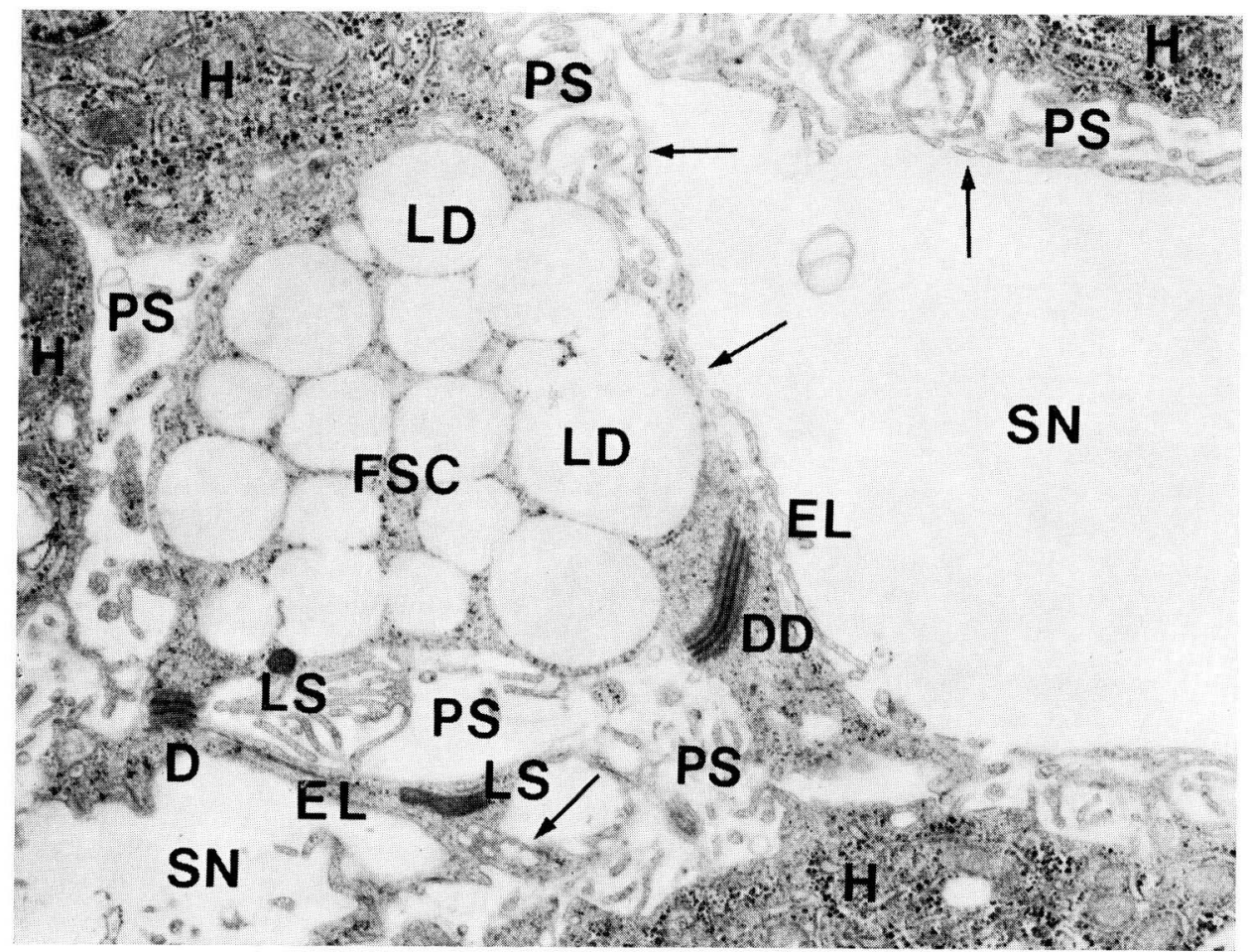

Fig. 10. Ito cell (FSC) with numerous lipid droplets $(L D)$. Along the endothelial lining $(E L)$ of the sinusoid ( $S N$ ) many sieve plates (arrows) are detected, one of which is tangentially cut. Two desmosomes are seen; one occurs between the cell body and a thick cytoplasmic process of Ito cells $(D D)$ and the other $(D)$ between a cytoplasmic process of the Ito cell and the endothelial lining ( $E L$ ) of sinusoid. $H$ hepatocytes, $L S$ lysosomes, $P S$ Disse's space. Flatfish liver. $\times 10,000$ 
other hand, the sinusoidal endothelial cell of the flatfish liver is occasionally connected by a desmosome either at its perikaryon or at a random site of its cytoplasmic extensions to the bulky cytoplasmic process of the subjacent hepatocyte beyond the Disse's space (Fig. 5, 6). These hepatocyte-endothelial cell junctions are not frequent. Desmosomes between the endothelial and Ito cell will be described elsewhere.

c. Ito cells or fat-storing cells are constant resident cells in the Disse's space, usually containing lipid droplets and lacking in the basal lamina. The Ito cells of the flatfish have multiple lipid droplets of small and medium size in variable amounts in the cytoplasm which frequently indent the nucleus (Fig. 4, 10,13). The lipid droplets have no limiting membrane, but they are surrounded by cytoplasmic microfilaments (Fig. 12, 14, 16). The shape of the Ito cell appears variable but is mostly elongated in profile along the endothelial lining (Figi. 4, 13). As is widely known, Ito cells send out cytoplasmic processes into the Disse's space (Fig. 5, 13, 15), but in the flatfish the so-called "subendothelial processes" (ITO and SHIBASAKI, 1968; ITO, 1973) appear less frequent than in other animals (Fig. 17). In the flatfish collected for this study, the amounts of lipid droplets stored in Ito cells were in general large, though they were widely variable from cell to cell. The so-called "empty fat-storing cells" which contain no or few lipid droplets were rare. They appear more slender as compared with Ito cells containing lipid droplets, but the ultrastructural features of the Ito cells are recognizable in detail, whereas in the lipid droplet-loaded cells they are either partially hidden or generally behind the cell inclusions. A relatively large Golgi complex occurs on one side of the nucleus, within which a diplosome or one of its paired centrioles is revealed (Fig. 4). Mitochondria are sparse and generally smaller than those of the hepatocyte (Fig. 11). Small dense bodies, or lysosomes, are randomly scattered in a small number (Fig. 4, 10-12). Cisternae of the RER are revealed in the empty Ito cell in considerable numbers (Fig. 11) throughout the cytoplasm, while they are hardly detectable in the lipid droplet-loaded cells (Fig. 10). Abundant free ribosomes are distributed throughout the cytoplasm except in the Golgi area. They are readily detectable in the cytoplasm between lipid droplets.

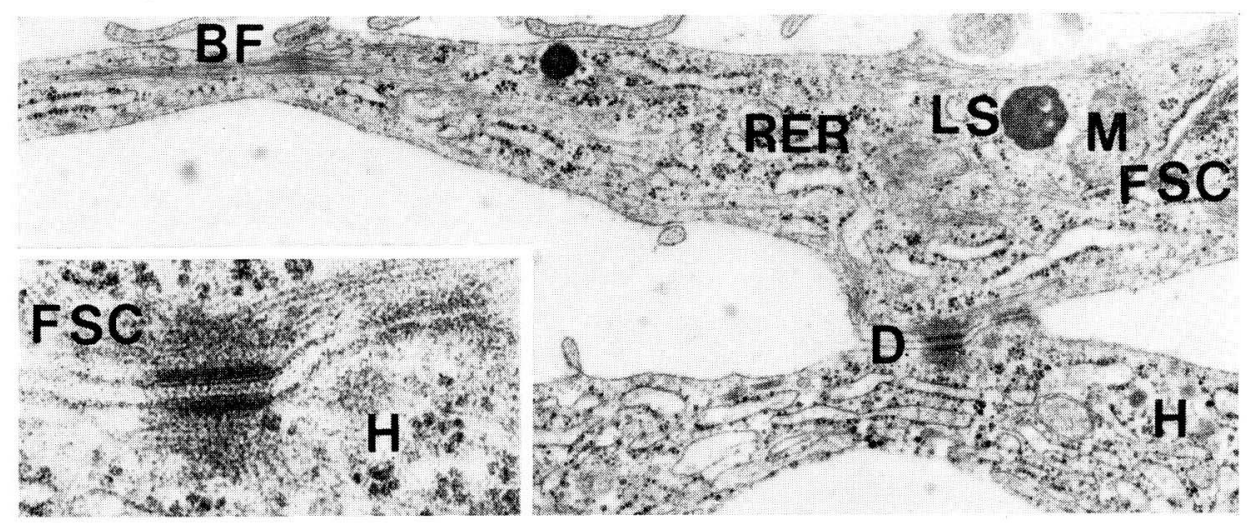

Fig. 11. Cytoplasmic process of an empty Ito cell (FSC). Note cisternae of the endoplasmic reticulum ( $R E R)$, many bundles of microfilaments $(B F)$ and solitary microtubules extended along the process. $D$ desmosome between Ito cell and hepatocyte $(H), L S$ lysosome, $M$ mitochondria. $\times 17,400$. Inset: High magnification of the desmosome between Ito cell (FSC) and hepatocyte (H). On both surfaces of the desmosome a conspicuous microfilament plexus is formed. The about $200 \AA$ wide intercellular space between the halves of symmetrically bepartite desmosome is traversed by delicate striations, in the middle of which an intermediate dotted line is seen. $\quad \times 55,000$ 


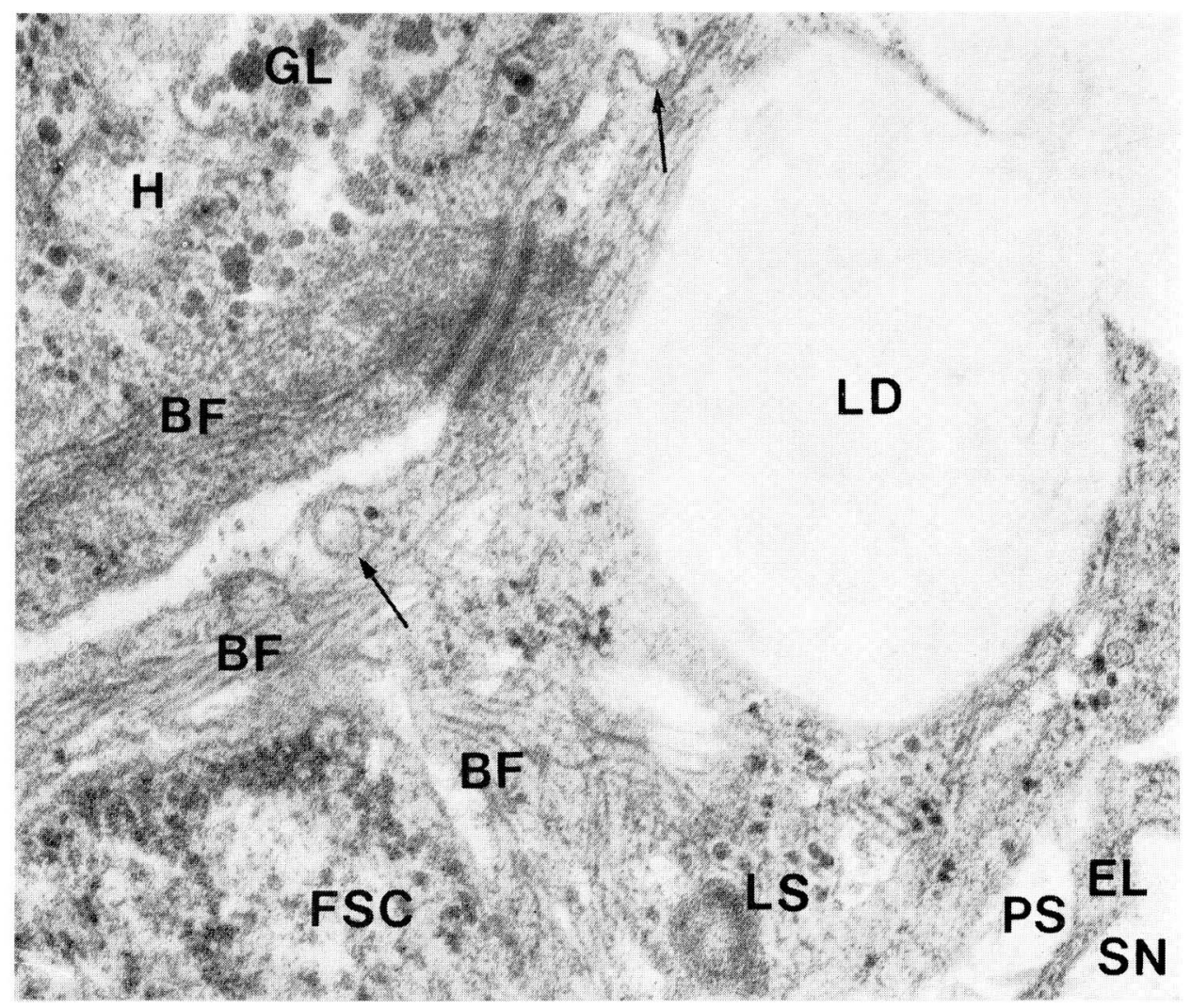

Fig. 12. Desmosome between an Ito cell (FSC) and a hepatocyte (H). Abundant microfilaments of two types of cell converge on the desmosome making loose bundles ( $B F$ ). The filament plexuses on both surfaces of the desmosome are not conspicuous and the striations traversing the intercellular space of the desmosome and the intermediate dotted line are hardly visible. EL endothelial lining of the sinusoid (SN), GL glycogen $\alpha$-particles, $L D$ lipid droplet, $L S$ lysosome, PS Disse's space, the arrows indicate a coated vesicle and a coated invagination of the plasma membrane. In the bottom left corner, the nucleus of the Ito cell is partly seen. Flatfish liver. $\times 65,000$

The most conspicuous cytological feature of flatfish fat-storing cells consists in that they contain abundant microfilaments oriented in variable directions, most frequently making compact or loose bundles, which, as previously described, also envelope lipid droplets (Fig. 12,14). As seen in Figures 5 and 11, microfilament bundles frequently are elongated along the long axis of the cell.

Microtubules are far less numerous than microfilaments, and individual ones have an almost straight coarse without forming bundles. Their orientation in the cytoplasm is indefinite, although they are at times oriented parallel to the long axis of the cytoplasm together with microfilaments (Fig. 11). Cytological signs suggestive of the micropinocytotic activity of the Ito cell are extremely rare, although coated invaginations and vesicles are occasionally detectable along the plasma membrane and in the cytoplasm (Fig. 12). A few glycogen $\beta$-particles are occasionally revealed, mainly along the outline of the lipid vacuoles.

The Ito cells of the flatfish liver often participate in the formation of desmosomal junctions with cells existing around them. They are most frequently observed between 


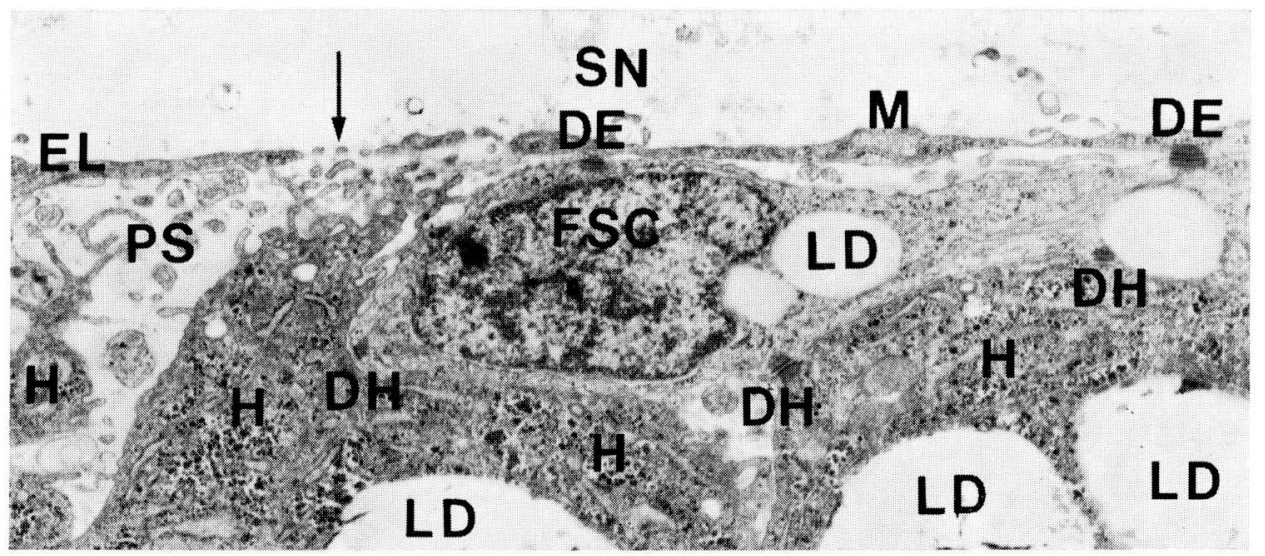

Fig. 13. Ito cell (FSC) in the Disse's space (PS), which is connected by desmosomes ( $D E$ ) with the endothelial lining ( $E L$ ) of sinusoid ( $S N$ ) both at its cell body and the cytoplasmic extension. This Ito cell is connected further with subjacent hepatocytes $(H)$ by three desmosomes ( $D H)$. LD lipid droplets, $M$ mitochondrion, the arrow indicates a sieve plates of the endothelial lining. Flatfish liver. $\times 10,000$

Ito cells and adjacent hepatocytes, so that almost all Ito cells are connected with subjacent hepatocytes through the desmosomes (Fig. 4, 5, 11-13 etc.). Desmosomes are formed between the cell body or cytoplasmic process of Ito cell on one hand, and hepatocytes on the other, so Ito cell is frequently provided with two or more desmosomes per cell to be connected with hepatocytes.

As observed in Figures 11 (inset) and 12, numerous microfilaments both of the hepatocyte and the Ito cell converge on the desmosome to anchor their attachment plaques, and, on both sides of the desmosome, make filament plexuses parallel to the attachment plaques across narrow lucent spaces, which are traversed by filaments coming from the plexuses to terminate at the attachment plaques.

The desmosomal junctions between the Ito cells and the sinusoidal endothelial cells are less frequent. They are formed between the cell body or cytoplasmic process of the Ito cell and cytoplasmic extension of the endothelial cell (Fig. 10, 13). Their fine structure almost agrees with that between the Ito cells and hepatocytes; cytoplasmic filaments both of the Ito cell and the endothelium converge on the desmosome first to form filament plexuses and then to anchor the attachment plaques across the lucent intervals between both structures (Fig. 14). As observed in Figures 13 and 14, a desmosomal junction between a hepatocyte and an Ito cell can be found occurring simultaneously with one between an Ito cell and an endothelial cell.

The third desmosomal junction in which the Ito cell participates is observed between the Ito cells themselves. These junctions are encountered in considerable numbers in the Disse's space of the flatfish liver (Fig. 10, 15). They are formed between the cell body and the thickened terminal portion of the cytoplasmic processes of a neighboring Ito cell (Fig. 10) or between two adjacent thickened end portions of cytoplasmic processes of neighboring Ito cells (Fig. 15). Upon observation of these junctional structures in higher magnifications (Fig. 15 inset, 16), it may be elucidated that in these cases the fine structures of the desmosomes agree almost completely with those of the above cases. However, the filament plexuses on the outside of the attachment plaques are most prominent. 


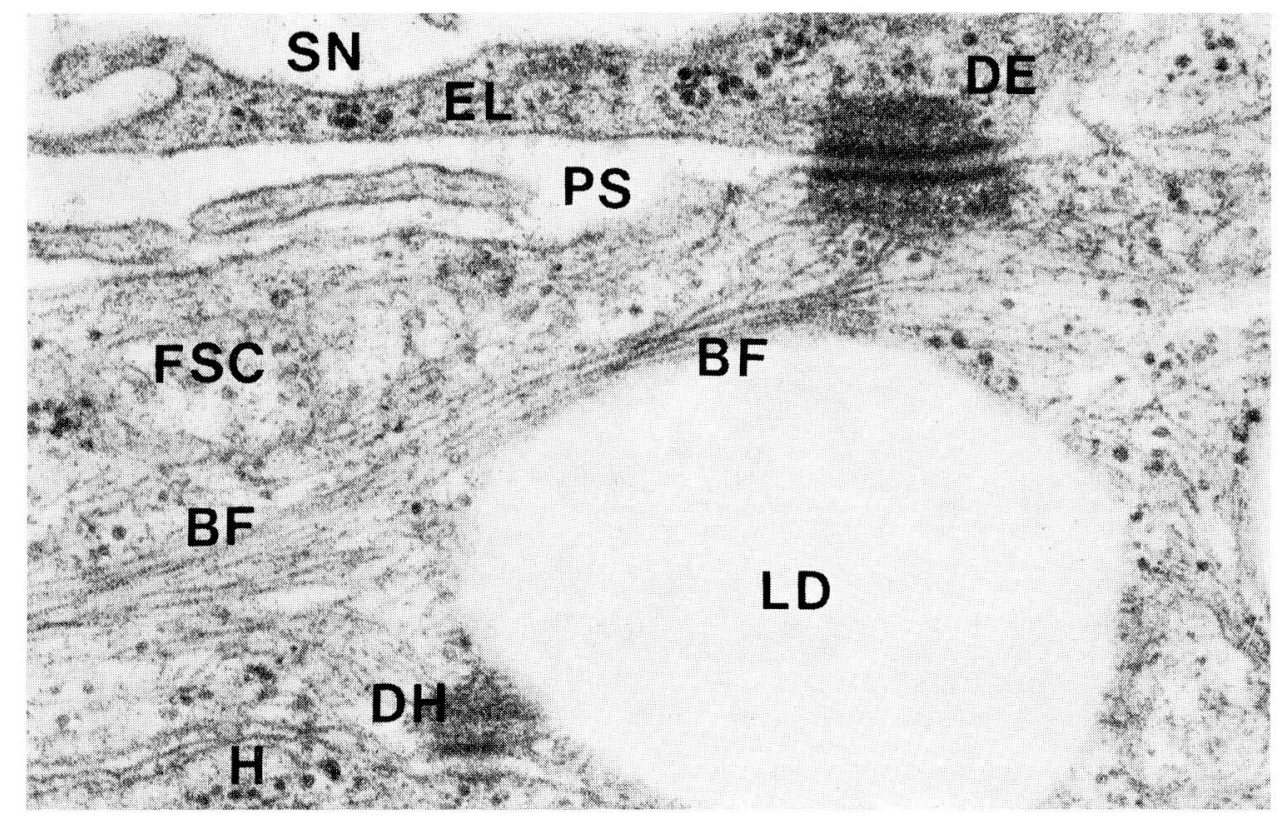

Fig. 14. Desmosome ( $D E$ ) between the endothelial lining ( $E L)$ of sinusoid $(S N)$ and a thick process of Ito cell (FSC) containing a lipid droplet $(L D)$. Another desmosome ( $D H$ ) between Ito cell and hepatocyte $(H)$ is found abutting on the lipid droplet. The former desmosome $(D E)$ agrees in structure with that between Ito cell and hepatocyte. The intermdiate line in the intercellular space, however, is missed. In the latter desmosome ( $D H)$, upper half belonging to Ito cell cytoplasm is only preserved. PS Disse's space containing microvilli of hepatocyte. Flatfish liver. $\times 55,000$

d. Collagen fibrils as revealed in mammalian livers have never been demonstrated in the Disse's space of the flatfish liver, but instead fine filaments oriented in irregular directions in indefinite locations of the Disse's space are revealed; and in places where they occur in large amounts, as shown in Figures 7, 8 and 17, they form irregular clusters or accumulations instead of bundles. In most parts of the Disse's sapce in the flatfish liver, the filaments are recognized only in small amounts (Fig. 9, 16) or hardly demonstrable (Fig. 5, 14).

\section{The Kupffer cell and other mesenchymal cells in the hepatic parenchyme}

As in the majority of fishes, Kupffer cells are not encountered in the hepatic sinusoid of the flatfish. However, macrophages are frequently found in the interhepatocytic space close to the Disse's space (Fig. 17). They are relatively large cells with irregular configurations. In the cytoplasm around the irregularly shaped nucleus, numerous dense bodies (lysosomes), large mitochondria, many cisternae of RER, and free polysomes are scattered. Occasionally small lymphocytoid cells occur in the same location, and are characterized by free ribosomes filling the cytoplasm surrounding a round nucleus.

\section{DISCUSSION}

In the flatfish liver, the hepatocytes are disposed around the bile canaliculi in roughly 


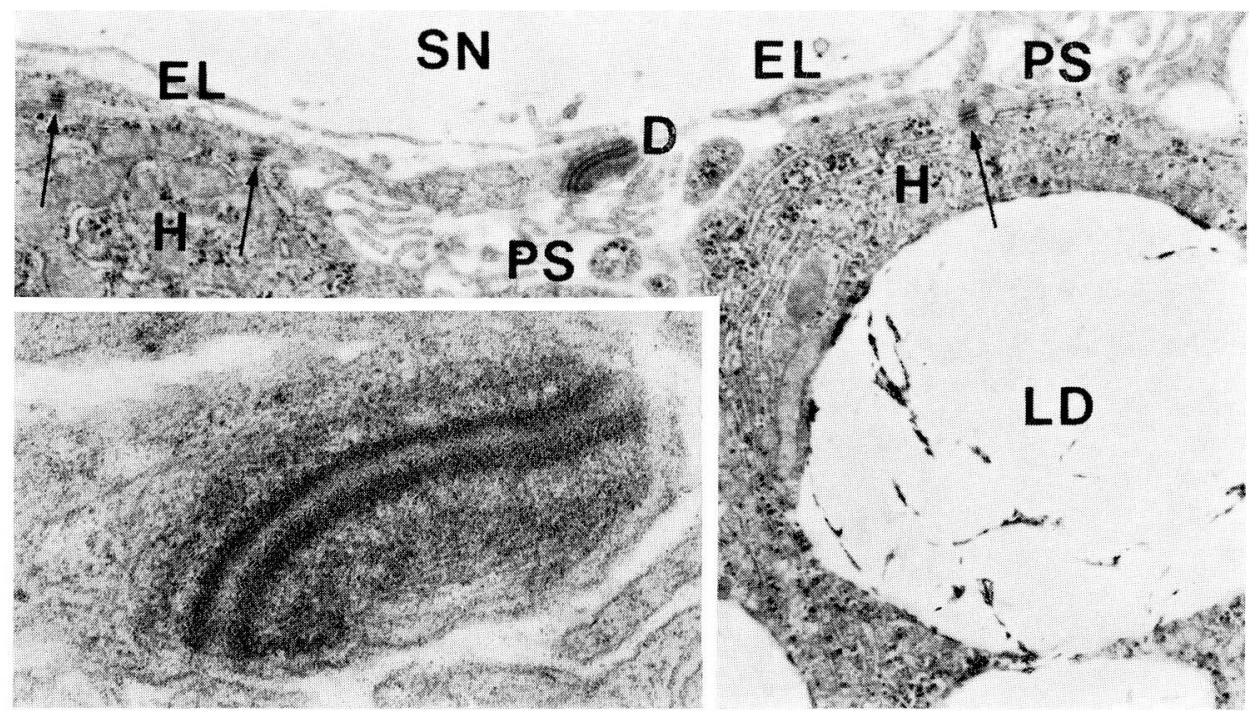

Fig. 15. Desmosomal junction $(D)$ between thickened end parts of cytoplasmic processes of Ito cells in the Disse's space (PS). The processes are connected also with subjacent hepatocytes $(H)$ by desmosomes (arrows). EL endothelial lining of sinusoid (SN), LD lipid droplet. Flatfish liver. $\times 8,900$. Inset: High magnification of the desmosome between Ito cell processes. Note microfilament plexuses along both surfaces of the desmosome. Many microfilaments derived from these plexuses traverse the lucent zones to terminate at desmosomal plaques. $\times 55,000$

the same fashion as in the tubular gland. Besides junctional complexes which connect hepatocytes abutting on the bile canalicular lumina, there are almost no connections such as gap junctions between adjacent hepatocyes, except for rare solitary desmosomes. Thus, the junctional complexes beneath the bile canalicular lumen are considered to be important structures for supporting the hepatic tissue.

The intralobular bile ductules running in the interhepatocytic space appear to play a role in supporting and fixing the hepatocytes, since the basal surface of their simple flat epithelium is connected with surrounding hepatocytes through many desmosomes. The intralobular bile ductules further serve as the internal framework for the hepatic tissue, because their epithelial cells are provided with abundant cytoplasmic microfilaments known as cytoskeletons.

In addition, the "desmosomal complexes" between hepatocytes, which were first revealed in this study are categorized as one of the supporting structures in the flatfish liver. Their unique accessory structures were compact bundles of microfilaments, running closely along the lateral surfaces of the desmosomes and sending out microfilaments to their attachment plaques.

The present study also revealed that, in the flatfish liver, the hepatocytic microvilli in the Disse's space frequently had a vesicular swelling at their distal ends. The large ones appeared to be invested merely by the plasma membrane. It is presumed that these apical vesicles of the hepatocytic microvilli are formed by accumulation of an unkown substance transported from the hepatocyte to the tip of the microvilli. The vesicular swellings of the microvilli are assumed to be pinched off into the Disse's space, because free vesicles probably derived from the apical vesicles of the microvilli are frequently encountered here and there in the Disse's space. These new findings 


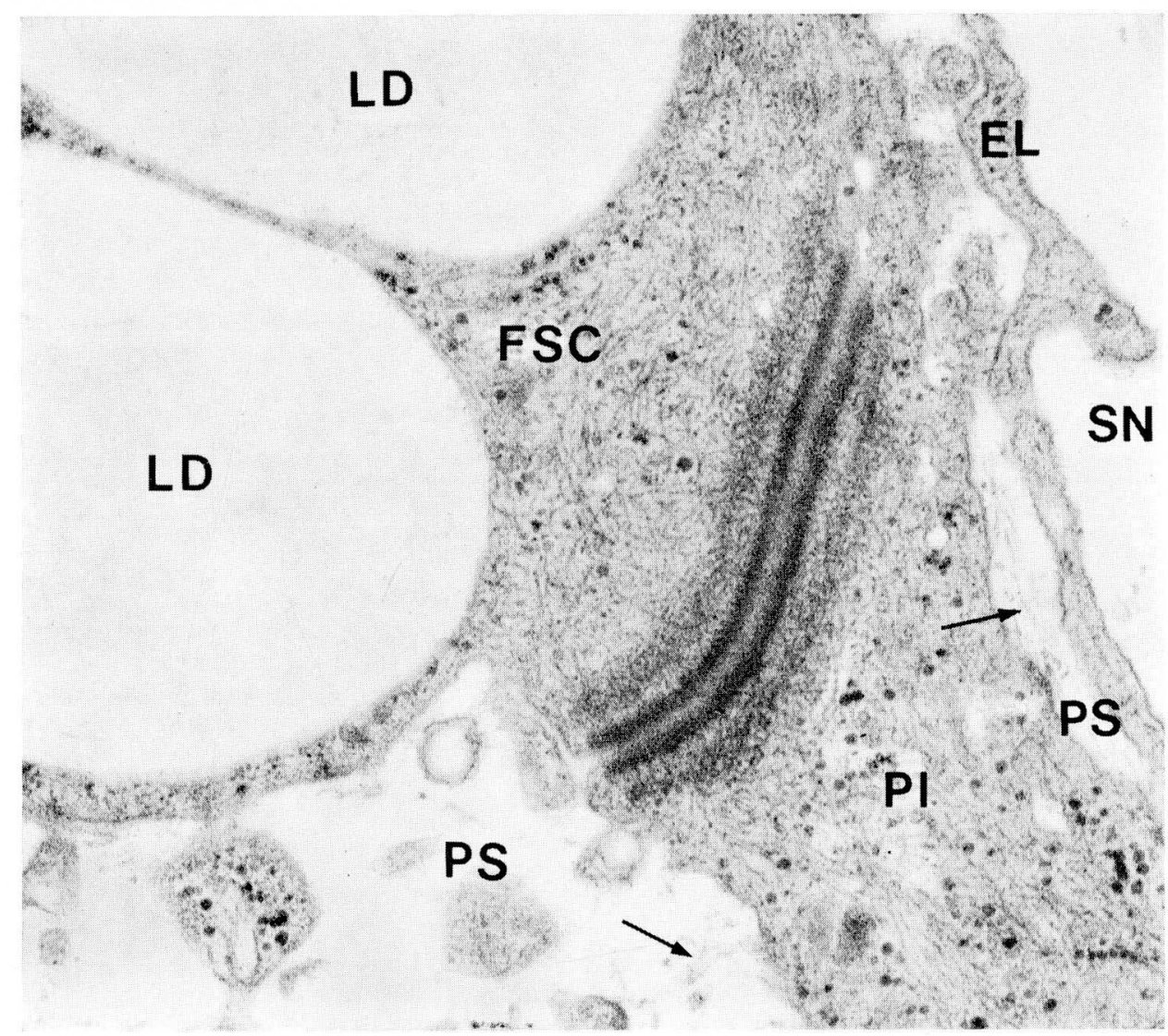

Fig. 16. Desmosome between a thick cytoplasmic process of an Ito cell $(P I)$ and another Ito cell's cell body $(E S C)$ filled with lipid droplets $(L D)$. This desmosome agrees in structure with that between Ito cell processes. EL endothelial lining of sinusoid (SN), PS Disse's space containing a few filaments (type IV collagen) (arrows) Flatfish liver. $\quad \times 45,000$

would support the speculation that hepatocytes of the flatfish liver discharge an unknown substance by means of the so-called "microapocrine mechanism" (Kurosumi, 1961) into the sinusoid via the Disse's space.

It was reported that both in the larval and adult lamprey the hepatocytes do not protrude microvilli into the Disse's sapce, but, instead, the perisinusoidal surfaces of the hepatocytes are deeply infolded covered by a basal lamina (Shin, 1977; Peek et al., 1979). By contrast, perisinusoidal microvilli of the hepatocyte are well developed in fishes, amphibia and reptiles (Spornitz, 1975; TAnuma and Ito, 1980; Fujita et al., 1980; Shin, 1981; TAIRA and Mutoh, 1981), while the perisinusoidal surface of hepatocytes of these lower vertebrates is lacking in the basal lamina. Thus, it has been suspected that subsequent to the appearance of microvilli, the basal lamina covering the perisinusoidal surface of the hepatocytes might disappear.

A number of authors have discussed the collagen fibrils (type III collagen, MilleR and Matukas, 1974, Popper, 1977) in the Disse's space of piscine livers; Tanuma and Ito (1980), Fujita et al. (1980), and Shin (1981) missed their existence, while SaKano and Fujita (1981) revealed them in some limited kinds of freshwater and marine teleostei and proposed an inverse proportion between the amounts of cellagen fibrils in the 


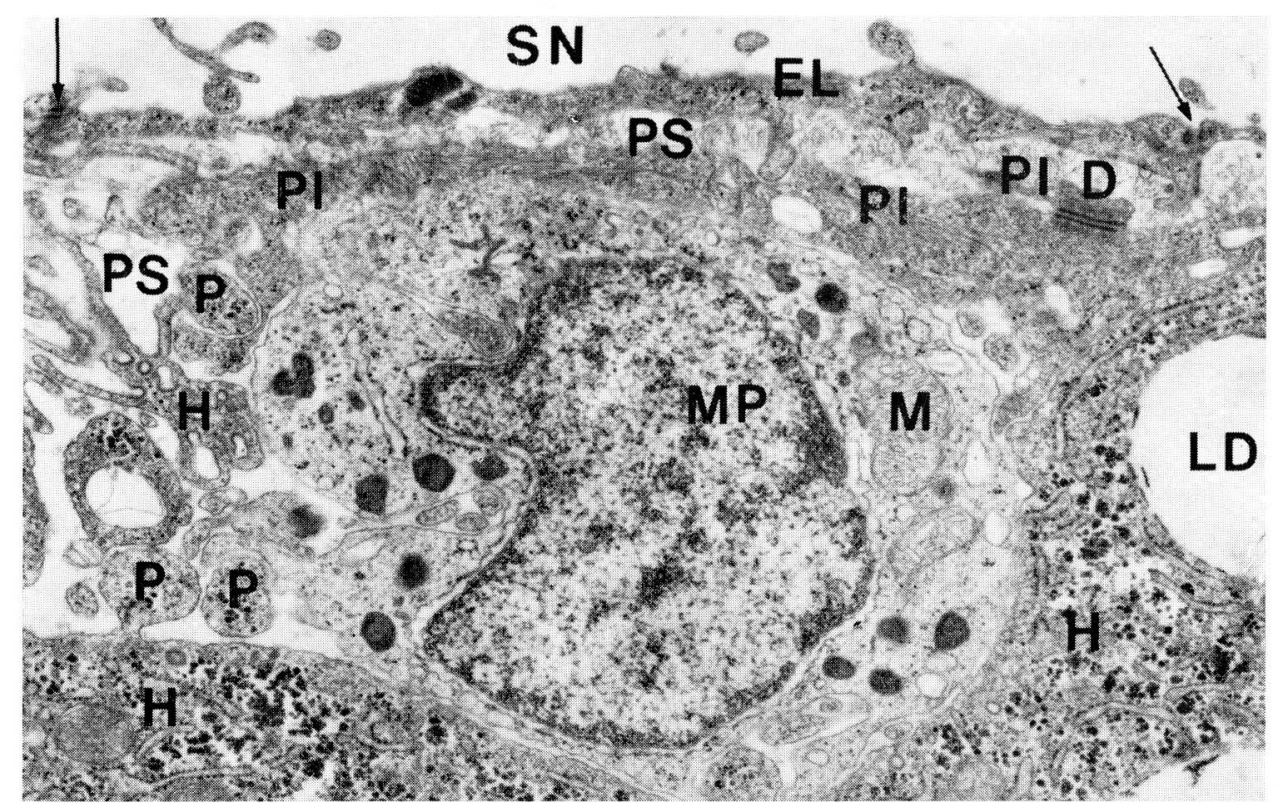

Fig. 17. A macrophage (MP) between hepatocytes $(H)$ and cytoplasmic processes (PI) of Ito cell. It contains numerous dense bodies, large mitochondria $(M)$, cisternae of RER and free ribosomes. Both endothelial lining ( $E L)$ of sinusoid ( $S N$ ) and Ito cell processes are strikingly rich in microfilaments. Disse's space (PS) contains abundant fine filaments (type IV collagen). $D$ desmosome between Ito cell processes, $L D$ lipid droplets, $P$ polypoid processes of hepatocyte, arrows indicate desmosomes between cytoplasmic extensions of endothelial cells. Flatfish liver. $\times 13,000$

Disse's sapce and the incidence of desmosomal junctions between the sinusoidal cells including the Ito cell. Nopanitaya et al. (1979a, b) revealed collagen fibrils in the Disse's space only around large sinusoids in five piscine species including goldfish. In lower vertebrates such as reptiles, amphibia and lamprey, collagen fibrils were demonstrated in the Disse's sapce by Spornitz (1975), Shin (1977), Peek et al. (1979) and Taira and Mutoh (1981). Tanuma and Ito (1980), however have revealed in crucian livers the presence of fine filaments probably belonging to type IV collagen (MiLLeR and Matukas, 1974; Popper, 1977) and proved that they increased in amount after administration of large doses of vitamin A.

It the present study on flatfish livers, fine filaments identical with those found in the crucian livers were revealed in the Disse's space. This possible type IV collagen was comprised of fine filaments measuring about $100 \mathrm{~A}$ in thickness oriented in irregular directions without forming bundles. It might be noteworthy that PEeK et al. (1979), in their electron microscopic study on larval lamprey livers, found not only collagen fibrils but also fine filaments in the Disse's space. This finding was thought to support the presumption that the fine filaments might possibly be the precursor of collagen fibrils, although the former in some species of lower vertebrates never develop into the latter. The previous and present findings, at any rate suggest that in fishes the occurrence of collagen fibrils in the Disse's space is generally rare; in other words the suppor tive elements of the piscine liver are more poorly developed than in the other kinds of lower vertebrates.

Sinusoidal endothelial cells of the flatfish liver agreed in structure with those of 
other fishes (Tanuma and Ito, 1980, Fujita et al., 1980; Shin, 1981). The images of the discontinuous endothelium with diaphragma-lacking fenestrae often gathered into clusters, "sieve plates", agreed with the findings in the goldfish (Nopanitaya et al., 1979a) and in the crucian liver (TANUmA and ITO, 1980). The discontinuous endothelium of the hepatic sinusoid is a common feature in lower vertebrates, i.e., reptiles, amphibia, fishes and cyclostomata (Spornitz, 1975; Shin, 1977; Peek et al., 1979; Tanuma and Ito, 1980; Fujita et al., 1980; TAIRA and Mutoh, 1981). Only in the lamprey has it been proposed that the basal lamina occurs not only at the base of the hepatocytes (PEEK et al., 1979) but also along the sinusoidal endothelium (SHIN, 1977) and that several fenestrae of the membraneous extension of the sinusoidal endothelium sometimes contain diaphragma (PEEK et al., 1979). One of the most conspicuous features of the sinusoidal endothelial cell in the flatfish liver is its extraordinary richness in cytoplasmic microfilaments, another noteworthy characteristic of the cell is the occurrence of desmosomes which connect neighboring sinusoidal endothelia as was first demonstrated by Fujita et al. (1980) in the goldfish liver. They revealed desmosomal junctions only between adjacent margins of the thicker portions of the processes of neighboring endothelial cells. In the flatfish livers, however, desmosomes can be demonstrated not only there but also between adjacent perikarya as well as between a perikaryon and the end part of the thicker portion of cytoplasmic process. In these sites the plasma membranes of the juxtaposed cell parts are paralleled for a fairly long distance across a cleft about $200 \AA$ wide. These appositions of the plasma membranes probably correspond to the "junctional complex" reported by WISSE (1970). Within these juxtaposed areas of the plasma membranes, solitary desmosomes appear, toward which cytoplasmic filaments converge to terminate at their desmosomal plaques. The desmosomal junctions between endothelial cells apparently reinforce their connection. Thus the entire tightly joined endothelium containing abundant cytoplasmic filaments seems to make up a strong framework supporting the hepatic tissue. On the other hand, the endothelial cells are often linked with adjacent Ito cells and hepatocytes by desmosomes. Desmosomal junctions between endothelial cells and hepatocytes are rare, but they can sometimes be observed between the perikaryon or cytoplasmic process of the endothelial cell and a bulky cytoplasmic process of the hepatocyte (Fujita et al., 1980; SHIN, 1981).

Ito cells with relatively large amounts of lipid droplets were frequently revealed in the Disse's space. Not very common were the so-called "empty Ito cells", whose existence has recently been recognized by FujiTA et al. (1980) and SHIN (1981) in goldfish livers and by TAIRA and МuтOH (1981) in reptile livers. The ultrastructural characteristics of the Ito cells were readily confirmed in the empty Ito cells. As recently reported by TANUMA and Ito (1980) and ShIN (1981) in their studies on the crucian and goldfish liver, the Ito cells of the flatfish liver also send out cytoplasmic processes in the Disse's space, but the "subendothelial processes" which have been thought to reinforce the endothelial lining of the sinusoid (Ito and Shibasaki, 1968; Ito 1973; Tanuma and Iто, 1978) are rarely encountered. The most striking feature of the ITO cell in the flatfish is its richness in cytoplasmic microfilaments, a finding which agreed with that by SHIN (1981) in his study on the goldfish liver.

NopanitayA et al. (1979a, b) reported that their "microfilament-rich perisinusoidal cells" in the Disse's space of some teleostean species, which have been identified by later authors as "empty fat-storing cells" (TANuma and Ito, 1980; FujITA et al., 1980; SHIN, 1981) were connected by desmosomes with hepatocytes as well as with endothelial cells. In succession, Tanuma and Ito (1980), Fujita et al. (1980), Shin (1981) and Sakano and Fujita (1981) described desmosomal connections between the Ito ceil and other 
sinusoidal cells as well as hepatocytes in the crucian, goldfish and many other piscine livers. Since these desmosomal junctions between sinusoidal cells including hepatocytes have never been observed in mammals, birds, reptiles, amphibia, and cyclostoma, they seemed to be specific junctional specialization limited only to the piscine liver. In the crucian liver, desmosomal junctions were revealed almost exclusively between Ito cells and hepatocytes (TANUma and ITO, 1980), but in the goldfish and several other fishes, desmosomal junctions were not limited to this site but also spread over between the Ito cells themselves and between Ito cells and endothelial cells. In the flatfish liver studied in the present study, desmosomes could be found in all these sites as seen in the goldfish liver (Fujita et al., 1980 and Shin, 1981).

Aside from the desmosomal junctions between the sinusoidal endothelial cells themselves, the most frequently observed were those between the Ito cell and hepatocyte, and in this case the occurrence of two or multiple desmosomes per one Ito cell was not rare.

Desmosomal junctions were most infrequent between the endothelial cell and hepatocyte, and in this case a bulky cytoplasmic process of the hepatocyte always mediated the junctions beyond the Disse's space. The next rarest desmosomal junctions were those between the Ito cell and endothelial cell. Desmosomal junctions between Ito cells themselves were rather frequently detected in the Disse's space; in this case, junctions between apposed large surfaces of the thickened end parts of the neighboring Ito cell processes were frequent while those between the cell body and the process were rare.

The function of the perisinusoidal desmosomal junctions is believed to be mechanical: they bind the microfilament-rich sinusoidal cells into a strong framework to support the architecture of the hepatic tissue, and if the circular chains of the endothelial cells as well as of the Ito cells around the sinusoid were actually contractile, then they would play a role in the regulation of the flow of the sinusoidal blood and in the elevation of the tension of the portal vein. By comparison of the findings in different fish species, SAKANO and Fujita (1981) pointed out that the population of desmosomes in sinusoidal cells seems to be compensatory to the amount of collagen fibrils in the Disse's space.

The desmosomes in the perisinusoidal area of the flatfish liver comprise plasma membranes of adjacent cells apposed in parallel, showing an intercellular space 200 $300 \AA$ wide which is traversed by delicate striations. In the middle of these striations a dotted line is occasionally observed especially in the desmosomes between the Ito cell and the hepatocyte. As is widely known, cytoplasmic microfilaments converge on the desmosome to terminate at the highly electron dense desmosomal plaque or to form narrow hair pin loops in the latter, thus turning back into the cytoplasm as proposed by Kelly (1966). In the case of desmosomes observed in this study, abundant microfilaments also converged on the desmosome, often forming bundles even in the hepatocytes which are generally known to be poor in filaments. According to Fujita et al. (1980), in the desmosomes between the sinusoidal cells of the goldfish liver, the converged filaments form compact bundles close to the desmosome and parallel with the cell surfaces as in the desmosomal complexes between flatfish hepatocytes reported in this study. In the desmosomes between the sinusoidal cells of the flatfish liver, abundant filaments formed, prior to arrival at the desmosomal plaques, a zone of plexuses or irregular networks which were extended along the desmosomal plaques acorss a narrow electron lucent zone. Microfilaments derived from the filament plexuses traversed obliquely or perpendicularly to the electron lucent zone to terminate in the plaque. Thus, the desmosomes found in the flafish liver exhibited a more complex fine structure 
than ordinary desmosomes. The striking accumulation and termination of abundant elements of the cytoskeleton at the desmosomes might probably serve for the maintenance of the strong reciprocal cohesion of cells by means of a high, induced rigidity of the paradesmosomal cytoplasm.

Although Kupffer cells have been revealed in the hepatic sinusoids of lower vertebrates such as lamprey (Shin, 1977; PeEK et al., 1979), amphibia (Spornitz, 1975) and reptiles (lizard, snake and turtle) (TAIRA and МuTOH, 1981), they have scarcely been revealed in piscine livers, or detected only in limited species (SchмidT, 1956, 1959; Iто, Watanabe and Takahashi, 1962; Tanuma and Ito, 1980; Shin, 1981; Sakano and Fujita, 1981). Awaya (1977) was able to reveal a few Kupffers in the ray, while he missed them in the crucian carp. Fujita et al. (1980) rarely found Kupffer cells in the sinusoid of the goldfish liver. According to Schmid (1959), Kupffer cells could only be demonstrated in the liver sinusoid of carp which had received prolonged stimulation to the histiocytes of the reticuloendothelial system. No Kupffer cell could be found in the flatfish liver examined. Noteworthily, however, is the finding that the flatfish liver frequently exhibited macrophages in the interhepatocytic space close to the Disse's space. It is worthwhile to recollect that several authors, studying livers in different vertebrate species (Tanuma and Ito, 1978; Tanuma, Оhata and Ito, 1981; Ohata, TANUMA and ITO, 1982) demonstrated that macrophages in the hepatic parenchyma could migrate through gaps or pores of the sinusoidal endothelial lining into the sinusoid and there transformed into Kupffer cells.

\section{REFERENCES}

Awaya, K.: Phylogeny of immune system and macrophage. (In Japanese). Taisha (Tokyo) 14: 1523-1534 (1977).

Fujita, H., T. Tamaru and J. Miyagawa : Fine structural characteristics of the hepatic sinusoidal walls of the goldfish (Carassius auratus). Arch. histol. jap. 43: 265-273 (1980).

Ito, T.: Recent advances in the study on the fine structure of the hepatic sinusoidal wall. Gunma Rep. Med. Sci. 6: 119-163 (1973).

Ito, T. and S. Shibasaki : Electron microscopic study on the hepatic sinusoidal wall and the fatstoring cells in the normal human liver. Arch. histol. jap. 29: 134-192 (1968).

Ito, T., A. Watanabe and Y. Takahashi : Histologische und cytologische Untersuchungen der Leber bei Fisch und Cyclostoma, nebst Bemerkungen über die Fettspeicherungszellen (Japanese text with German abst.) Arch. histol. jap. 22: 429-463 (1962).

Kelly, D.: Fine structure of desmosomes, hemidesmosomes and an adepidermal globular layer in developing newt epidermis. J. Cell Biol. 2B: 51 (1966).

Kurosumi, K.: Electron microscopic analysis of the secretion mechanism. Int. Rev. Cytol. 11: 1-124 (1961).

Miller, E. J. and V. T. Matukas : Biosynthesis of collagen. The biochemist's view. Fed. Proc. 33: 1187-1204 (1974).

Nopanitaya, W., J. L. Carson, J. W. Grisham and J. G. Aghajanian: New observations on the fine structure of the liver in goldfish (Carassius auratus). Cell Tiss. Res. 196: 249-261 (1979a).

Nopanitaya, W., J. G. Aghajanian, J. W. Grisham and J. L. Carson : An ultrastructural study on a new type of hepatic perisinusoidal cell in fish. Cell Tiss. Res. 198: 35-42 (1979b).

Ohata, M., Y. Tanuma and T. Ito: Electron microscopic study on avian livers with special remarks on the fine structure of sinusoidal cells. Okajimas Fol. Anat. jap. 58: 325-368 (1982).

Peek, W. D., E. W. Sidon, J. H. Youson and M. M. Fisher: Fine structure of the liver in the 
larval lamprey, Petromyzon marinus L.: Hepatocytes and sinusoids. Amer. J. Anat. 156: 231-249 (1979).

Popper, H.: Summary. In: (ed. by) E. Wisse and D. L. Knook: Kupffer cells and other sinusoidal cells. Elsevier/North-Holland Biomedical Press, Amsterdam, 1977 (p. 509-514).

Sakano, Y. and H. Fujita: Fine structural characteristics of the liver in the fish. (Abstract in Japanese) Acta anat. nippon. 56: 236 (1981).

Schmidt, F. C.: Über das Vorkommen von Kupfferschen Sternzellen in der Leber von Fischen (Cyprinus carpio). Z. mikrosk.-anat. Forsch. 62: 487-520 (1956).

: Vorkommen und Verhalten von Sternzellen der Leber des Aales und ihre Beziehung zum reticulo-endothelialen System. Z. Zellforsch. 49: 401-417 (1959).

Shin, Y. C.: Some observations on the fine structure of lamprey liver as revealed by electron microscopy. Okajimas Fol. anat. jap. 54: 25-60 (1977).

: Some observations on perisinusoidal lipocyte (Ito cell) of Carassius auratus liver as revealed by electron microscopy. Acta anat. nippon. 56: 133-144 (1981).

Spornitz, U. D.: Studies on the liver of Xenopus laevis. I. The ultrastructure of the parenchymal cell. Anat. Embryol. 146: 245-264 (1975).

Taira, K. and H. Mutoh : Comparative ultrastructural study on the Ito cells in the liver in some reptiles. Arch. histol. jap. 44: 373-384 (1981).

Tanuma, Y. and T. Ito: Electron microscope study on the hepatic sinusoidal wall and fat-storing cells in the bat. Arch. histol. jap. 41: 1-39 (1978).

: Electron microscopic study on the sinusoidal wall of the liver of the crucian, Carassius carassius, with special remarks on the fat-storing cell (FSC). Arch. histol. jap. 43: 241-263 (1980).

Tanuma, Y., M. Ohata and T. Ito: An electron microscopic study of kitten liver with special reference to fat-storing cells. Arch. histol. jap. 44: 23-49 (1981).

Wisse, E.: An electron microscopic study of the fenestrated endothelial lining of rat liver sinusoids. J. Ultrastr. Res. 31: 125-150 (1970)

\author{
田沼裕 \\ =173 東京都板橋区加賀 2-11-1 \\ 帝京大学医学部 \\ 第一解剖学教室
}

Dr. Yutaka TANumA

Department of Anatomy

Teikyo University School of Medicine

Kaga 2-11-1, Itabashi-ku

Tokyo, 173 Japan 